\title{
Surgically Induced Corneal Astigmatism Following Intravitreal Ranibizumab Injection
}

\author{
Tolga Kocatürk ${ }^{*}, 1$, Erol Erkan ${ }^{1}$, Sait Eğrilmez ${ }^{2}$, Harun Çakmak ${ }^{1}$, Sema O. Dündar ${ }^{1}$ and Volkan Dayanir ${ }^{1}$ \\ ${ }^{I}$ Department of Ophthalmology, Faculty of Medicine, Adnan Menderes University, Aydin, Turkey \\ ${ }^{2}$ Department of Ophthalmology, Faculty of Medicine, Ege University, Izmir, Turkey
}

\begin{abstract}
Purpose: To evaluate surgically induced astigmatism (SIA) after an intravitreal ranibizumab (IVR) injection.
Methods: Fifty eight eyes of 58 patients who underwent IVR injection due to age-related macular degeneration (wet form) or macular edema were included in this study. Patients' pre- and postoperative detailed ophthalmologic examinations were done and topographic keratometric values (K1, K2) were noted. Pre- and postoperative measurements were compared.

Results: The mean preoperative astigmatism of 0.87 Diopters (D) was found to be $0.95 \mathrm{D}, 0.75 \mathrm{D}, 0.82 \mathrm{D}$ and $0.78 \mathrm{D}$ on the 1st day, 3rd day, $1 \mathrm{st}$ week and 1st month, respectively. After injection, absolute change in astigmatism was found to be $0.08 \mathrm{D}, 0.12 \mathrm{D}, 0.05 \mathrm{D}$ and $0.09 \mathrm{D}$ on the 1 st day, 3rd day, 1st week and 1st month, respectively. The absolute change in astigmatism seemed to be insignificant in terms of refractive analysis, however; when we performed a vectorial analysis, which takes into account changes in the axis of astigmatism, the mean value of induced astigmatism were found to be $0.33 \pm 0.22 \mathrm{D}, 0.32 \pm 0.29 \mathrm{D}, 0.41 \pm 0.37 \mathrm{D}, 0.46 \pm 0.32 \mathrm{D}$ on the 1 st day, 3rd day, 1 st week and on 1 st month, respectively.

Conclusion: Intravitreal injection is a minimally invasive ophthalmologic procedure, however; it may still cause statistically significant induced astigmatism when evaluated from a vectorial point of view.
\end{abstract}

Keywords: Intraocular pressure, intravitreal injection, ranibizumab, surgically induced astigmatism, vectorial analysis.

\section{INTRODUCTION}

Intravitreal injection of humanized anti-vascular endothelial growth factor (anti-VEGF) is widely performed for diabetic macular edema [1], age-related macular degeneration [1] and central retinal vein occlusion treatment $[2,3]$. Intravitreal anti-VEGF agents prevent pathological neovascularization in the eye. However, they may cause both systemic and ocular complications including strokes, transient ischemic attacks, retinal pigment epithelial tears, intraocular pressure-related events, endophthalmitis, traumatic cataracts and refractive errors $[4,5]$.

After any surgical intervention, refractive changes may occur such as astigmatism. Astigmatism is one of the important refractive errors affecting the visual acuity. Astigmatism is caused by the different refractive powers in different axis and is affected by ocular interventions [6]. Astigmatism is possibly influenced by intravitreal injections too, because of mechanical affect of entering needle through ocular tissues such as conjunctiva, tenon, sclera, choroid and vitreous besides intraocular volume changes.

There is no study in the literature focusing on the effects of intravitreal anti-VEGF injection on surgically induced

*Address correspondence to this author at the Department of Ophthalmology, Faculty of Medicine, Adnan Menderes University, Aydın, Turkey; Tel: 009053334441 11; Fax: 009025621464 95;

E-mail: tolgakocaturk@gmail.com astigmatism (SIA). To the best of our knowledge, this study is the first clinical study which investigates SIA both in dioptric power and vectorial aspect.

\section{METHODS}

We reviewed the medical records of the patients who had undergone IVR injection for diabetic macular edema, wetform age-related macular degeneration or central retinal vein occlusion. All patients received only one injection (first injection) through the study. Patients who had multiple IVR injections prior to the study were not included in the study. Patients with coexisting ocular pathology (keratoconus, corneal opacities, etc.), previous history of ocular surgery, follow-up by duration less than a month, poor cooperation to corneal topography were excluded. Inform consent was obtained from the patients. The study was approved by university's local ethics committee and was performed according to the Declaration of Helsinki.

58 eyes of 58 consecutive patients who had their first IVR injection were enrolled in this study. All patients underwent a detailed ophthalmological examination including measurement of IOP with Goldmann Applanation Tonometre and keratorefractometric examination (Orbscan II $\mathrm{Z}$, Bausch \& Lomb) in the pre- and postoperative period. Corneal topographic values including K1, K2, axis and IOP levels were noted from patients' postoperative follow-ups. SIA was calculated with the Vectorial Analysis Program in 
Astigmatism software $[7,8]$. The patients were underwent an intravitreal injection of $0.5 \mathrm{mg}$. ranibizumab (Lucentis; Novartis, Bulach, Switzerland) under topical anesthesia and they were examined on the 1 st day, 3 rd day, 1 st week and 1 st month after the injection.

\section{Surgical Technique}

Proparacaine hydrochloride eye drops were instilled on the eye before the injection. The area is swabbed with ophthalmologic 5\% povidone iodine $\left(\right.$ Betadine $^{\circledR}$ ) with instillation of the conjunctiva and the superior and inferior conjunctival fornices. The injection site was located at the pars plana between 3.5 (in pseodophakic patients) and $4 \mathrm{~mm}$ (in phakic patients) posterior to the limbus superotemporally. The needle (30-gauge) is inserted through the conjunctiva, perpendicular to the eye wall, aiming toward the center of the globe. The therapeutic agent is injected slowly, and then the needle is removed gently. The injection site was observed for any reflux of the agent. An antibiotic eye drop was instilled and an eye-shield was placed over the eye.

\section{Statistically Analysis}

Kolmogorov-Smirnov test was used to assess the normality of numeric variables. For the normally distributed variables, the results were expressed as a mean \pm standard deviation. For the non-normally distributed variables, the results were expressed as median (25-75 percentiles). Significance was defined as $<0.05$. Pearson Test was performed to study correlation between SIA and IOP changes. Wilcoxon Test was performed to compare SIA values.

\section{Repeatability Analysis}

A repeatability analysis of the Orbscan II Z autokeratorefractometer was performed based on Bland and Altman's suggestion [9]. Ten measurements of a healthy individual were obtained and used for repeatability analysis. Between each measurement the individual was asked to blink and lean back to simulate a different measurement session. In repeatability analysis, any astigmatism smaller than 0.16 diopters (D) was accepted in the "variable interval" which changes according to device and operator. The realinduced changes in vectorial astigmatism greater than $0.16 \mathrm{D}$ were defined as SIA.

\section{Vector Analysis}

Surgically induced astigmatism was calculated with the Vectorial Analysis Program in Astigmatism software [7,8].

\section{RESULTS}

Different types of surgical procedures may induce astigmatism in the post-procedural period. In this study, we reported the astigmatic effect of IVR injection. Various retinal diseases (wet-form age-related macular degeneration, diabetic macular edema or vascular disorders) are treated with intravitreal injections of ranibizumab.
The demographic data of the subjects are given in Table 1. When we calculated the absolute astigmatism, the mean preoperative astigmatism of $0.87 \mathrm{D}$ was found to be $0.95 \mathrm{D}$ in postop-1st day; $0.75 \mathrm{D}$ in postop-3rd day; $0.82 \mathrm{D}$ in postop-1st week; and $0.78 \mathrm{D}$ in postop-1st month. When compared with the preoperative period, the absolute change in astigmatism was found to be $0.08 \mathrm{D}$ on the 1 st day, $0.12 \mathrm{D}$ on the 3rd day, $0.05 \mathrm{D}$ in the $1 \mathrm{st}$ week and $0.09 \mathrm{D}$ in the $1 \mathrm{st}$ month postoperatively. These differences seem to be insignificant in terms of magnitude of astigmatism (Table 2). However, when we performed the vectorial analysis which takes into account changes in the axis of astigmatism, the mean arithmetic values of induced astigmatism were found to be $0.33 \pm 0.22 \mathrm{D}$ on the 1 st day, $0.32 \pm 0.29 \mathrm{D}$ on the $3 \mathrm{rd}$ day, $0.41 \pm 0.37 \mathrm{D}$ in the 1 st week and $0.46 \pm 0.32 \mathrm{D}$ in the $1 \mathrm{st}$ month postoperatively (Fig. 1). The mean vectorial values of induced astigmatism (centroid) were found to be $0.03 \alpha 71$ on the 1 st day, $0.07 \alpha 81$ on the 3 rd day, $0.12 \alpha 107$ in the 1 st week and $0.08 \alpha 109$ in the 1 st month postoperatively (Table 2) (Figs. 2, 4).

Table 1. Demographic data of the subjects.

\begin{tabular}{|l|c|}
\hline $\begin{array}{l}\text { Gender }(\mathrm{n}) \\
\text { Female } \\
\text { Male }\end{array}$ & $14(\% 24.1)$ \\
\hline Age & $44(\% 75.9)$ \\
\hline Right/Left & $67,7 \pm 10.1$ \\
\hline
\end{tabular}

Table 2. Vectorial means of induced astigmatic values are seen.

\begin{tabular}{|c|c|}
\hline Postoperative & Vectorial Mean of Induced Astigmatism (Centroid) \\
\hline \hline $1^{\text {st }}$ Day & $0.03 \alpha 71$ \\
\hline $3^{\text {rd }}$ Day & $0.07 \alpha 81$ \\
\hline $1^{\text {st }}$ Week & $0.12 \alpha 107$ \\
\hline $1^{\text {st }}$ Month & $0.08 \alpha 109$ \\
\hline
\end{tabular}

The mean IOP of the patients preoperatively and postoperatively are presented in Fig. (3). We haven't found any correlation between SIA and IOP changes (Pearson Test) (Table 3). The IOP changes were found to be statistically significant except changes between 3rd day-1st week $(p=0.512)$. When we compare SIA values between each other (1st, 3rd days, 1st week, 1st month) the changes in SIA were found to be statistically insignificant according to Wilcoxon Test.

Vectorial change in SIA at the first one-month period after intravitreal treatment was found to be bigger than the variation limit connected with the device and the user's measurement variability. These results have the highest values at postoperative 1st month. Although the process was applied without incision, IVR injection caused changes in keratometric values and resulted in statistically significant induced astigmatism, due to intraocular pressure changes, keratometric changes in wound healing process at the needle entering area. When considering the axial change in astigmatism, we found measurable difference vectorially in SIA. 


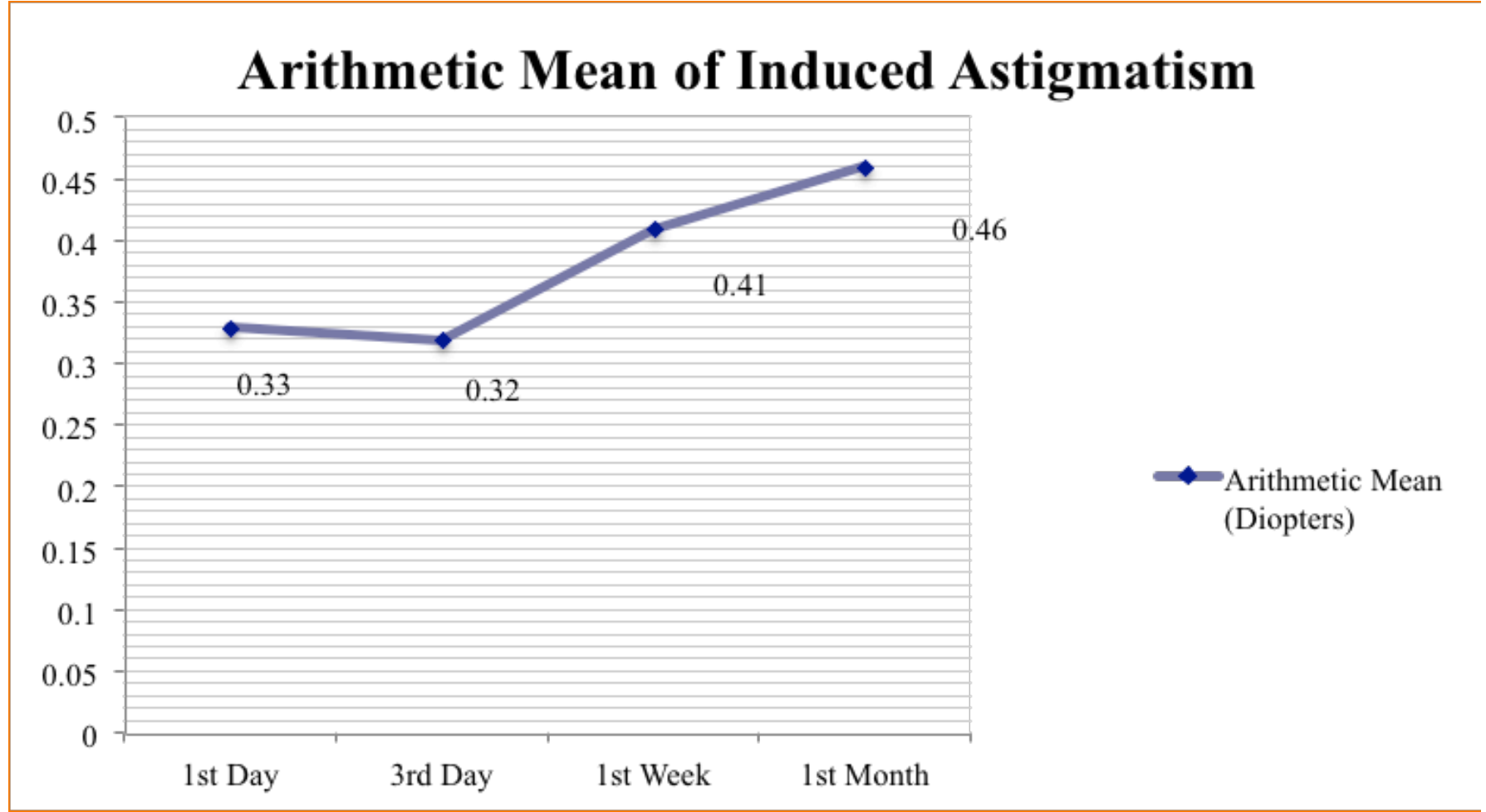

Fig. (1). Arithmetic means of induced astigmatism at follow-ups.

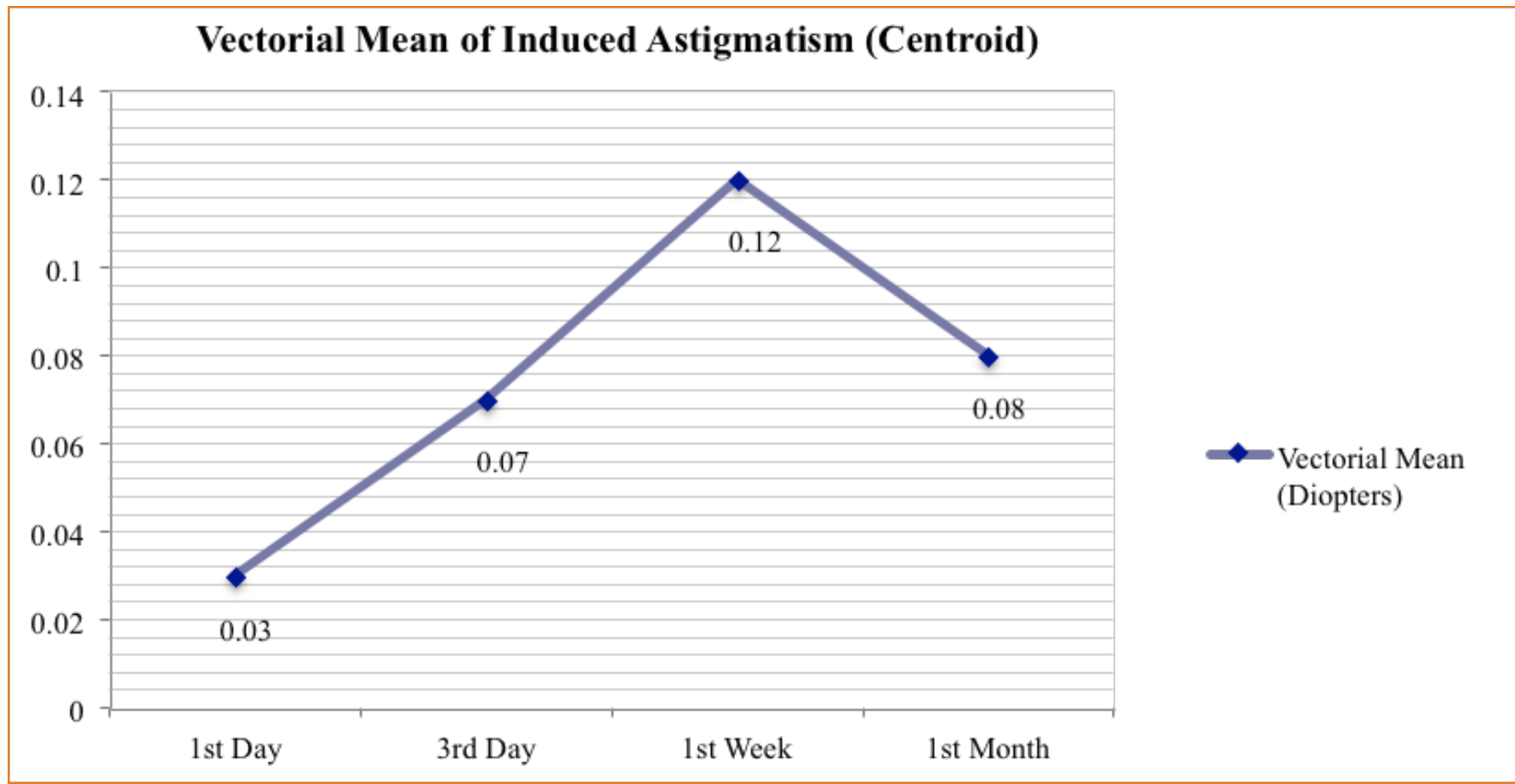

Fig. (2). Vectorial means of induced astigmatism (centroid) at follow-ups.

In our study, we didn't encounter any serious complications like; stroke, transient ischemic attack, retinal pigment epithelial tears, cataract or zonule dialysis and etc. Only in a few patients subconjuctival hemorrhage lasting no more than one day were seen.

\section{DISCUSSION}

Intravitreal injections are growing in numbers in recent years. The penetration of a needle through ocular tissues has an astigmatic effect in IVR procedure. Intraocular volume 
changes is also another reason that causes astigmatism. Pars plana is becoming more important place for ocular interventions such as IVR and small-gauge vitrectomies. Instrumentation is getting smaller during years, today $25-$ or 27 -gauge vitrectomies are performed instead of 20-gauge standard pars plana vitrectomy.

Table 3. Correlation analysis between SIA and IOP (Pearson Test).

\begin{tabular}{|c|c|c|}
\hline Days & P Values & R Values \\
\hline \hline $1^{\text {st }}$ Day & $\mathrm{p}: 0,472$ & $\mathrm{r}:-0,096$ \\
\hline $3^{\text {rd }}$ Day & $\mathrm{p}: 0,289$ & $\mathrm{r}: 0,142$ \\
\hline $1^{\text {st }}$ Week & $\mathrm{p}: 0,292$ & $\mathrm{r}:-0,141$ \\
\hline $1^{\text {st }}$ Month & $\mathrm{p}: 0,209$ & $\mathrm{r}:-0,167$ \\
\hline
\end{tabular}

In the literature, we could not find any study about astigmatic effect of IVR. However, vitrectomy and IVR have common points such as location of the surgery, intraocular volume change and size of instrumentation. Okamoto et al. [10] reported that 32 patients who underwent 25-gauge transconjunctival sutureless vitrectomy and 25 eyes of 24 patients who underwent 20-gauge standard pars plana vitrectomy were evaluated in terms of corneal astigmatic changes. In the 25-gauge group, no significant changes were observed in corneal topography [10]. In the 20-gauge group, the spherical magnitude did not change, whereas regular astigmatism, asymmetry, and higher-order irregularity were seen to increase significantly at 2 weeks after vitrectomy and returned to preoperative levels after 1 month [10]. In recent years, no significant corneal topographic changes were observed and it was reported that SIA was not induced after vitrectomy [11,12]. Sinha et al. [13] reported that corneal elevations were significantly increased and the posterior corneal surface was affected after the vitreoretinal surgeries [13]. Shibata et al. reported that refractive changes in corneal shape may occur after the 23-gauge vitreo-retinal surgery [14].

Due to change in the volume of the posterior segment of the eye after IVR injection, IOP changes in the early postoperative period should be considered to affect the corneal curvature and cause the induced astigmatism. Values of corneal astigmatism were seen to increase from the first week. A large incision is not made in this process, whereas spot sized tissue damage were made on the tissues from conjunctiva till vitreous. The wound healing process which starts from the moment of injection would affect the corneal astigmatism. Since, IOP changes have no effect on SIA according to our statistical analysis, wound healing processes may play more prominent role in microstructural level in terms of SIA.

Absolute astigmatism seems to be insignificant in terms of clinical practice for clinicians; however, when we consider SIA with cylinderical power and axial difference [refractive], the changes can be seen to be measurable and noteworthy.

Our paper is a fundamental study which investigated SIA with magnitude and meridional changes following IVR injection. There is no study in the literature focusing on the effects of IVR injection on SIA. To the best of our knowledge, this study is the first clinical study which investigates SIA both in dioptric power and vectorial aspects.

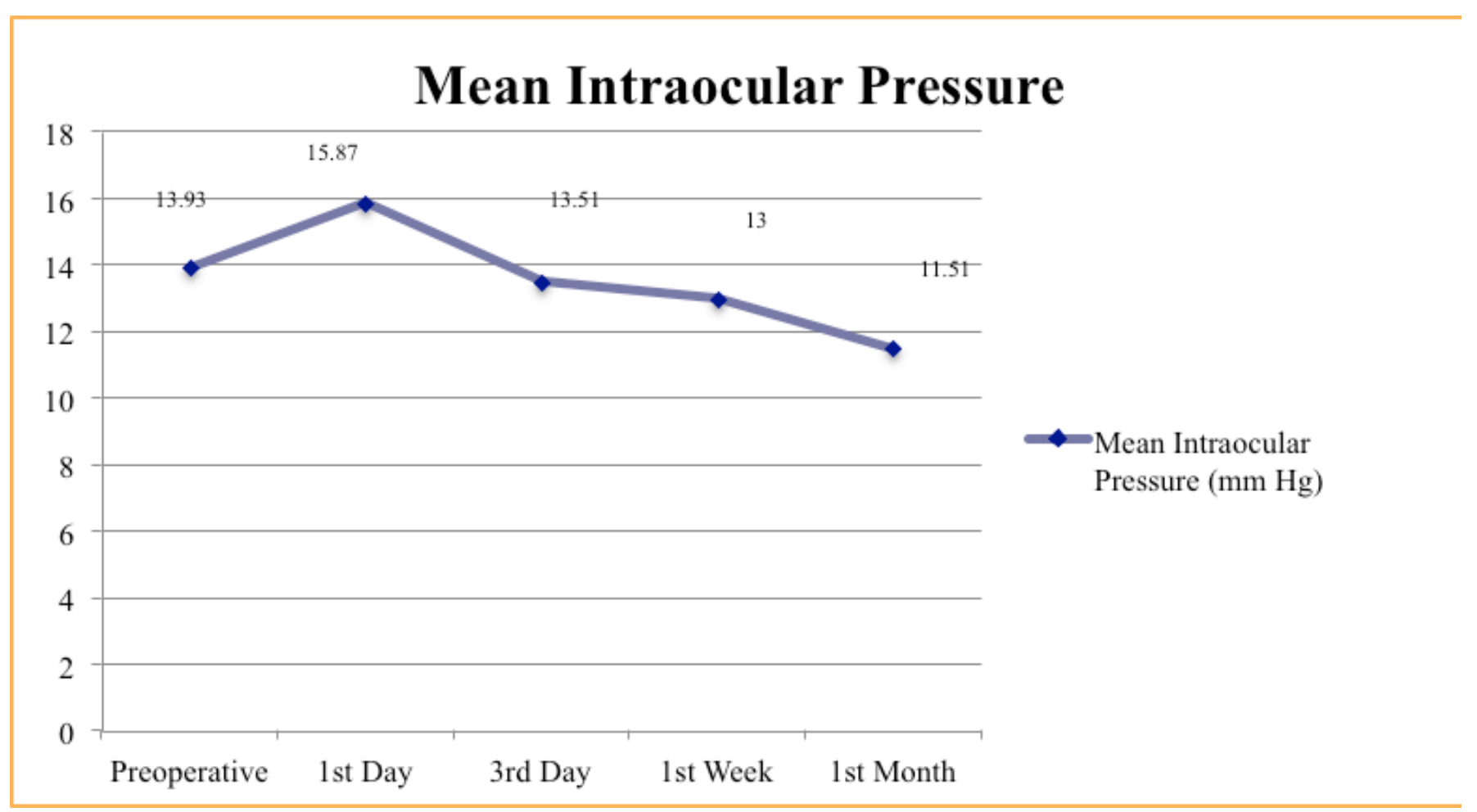

Fig. (3). Mean intraocular pressure alterations at follow-ups. 


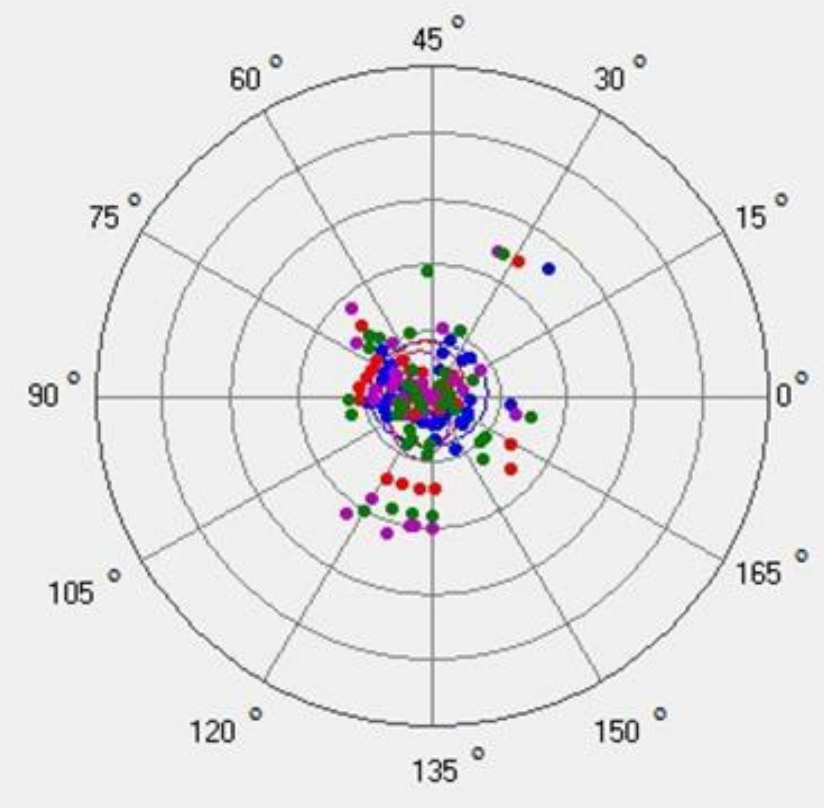

\section{Every circle represents $0,50 \mathrm{D}$ \\ The outer circle represents $2,50 \mathrm{D}$}

Fig. (4). Demonstrating the surgically induced astigmatism distribution of every patient on the vectorial map. Blue, red, purple and green dots represent $1^{\text {st }}$ day, $3^{\text {rd }}$ day, $1^{\text {st }}$ week and $1^{\text {st }}$ month values, respectively.

\section{CONFLICT OF INTEREST}

All authors have completed and submitted the ICMJE Form for Disclosure of Potential Conflicts of Interest, and none were reported.

\section{ACKNOWLEDGEMENTS}

Declared none.

\section{REFERENCES}

Fong AHC, Lai TYY. Long-term effectiveness of ranibizumab for age-related macular degeneration and diabetic macular edema. Clin Interv Aging 2013; 8: 467-83.

[2] Varma R, Bressler NM, Suñer I, et al. Improved vision-related function after ranibizumab for macular edema after retinal vein occlusion: results from the BRAVO and CRUISE trials. Ophthalmology 2012; 119(10): 2108-18.

[3] Risard SM, Pieramici DJ, Rabena MD, et al. Intravitreal ranibizumab for macular edema secondary to central retinal vein occlusion. Retina 2011; 31(6): 1060-7.

[4] Holz FG, Bandello F, Gillies M, et al. Safety of ranibizumab in routine clinical practice: 1-year retrospective pooled analysis of four European neovascular AMD registries within the LUMINOUS programme. Br J Ophthalmol 2013; 97(9): 1161-7.

[5] Schwartz SG, Flynn HW Jr. Endophthalmitis associated with intravitreal anti-vascular endothelial growth factor injections. Curr Ophthalmol Rep 2014; 2: 1-5.
[6] Moon NJ, Lee HI, Kim JC. The changes in corneal astigmatism after botulinum toxin-a injection in patients with blepharospasm. J Korean Med Sci 2006; 21(1): 131-5.

[7] Egrilmez S, Dalkilic G, Yagci A. Vector analysis software on analyzing astigmatism. Turk J Ophthalmol 2003; 33: 404-16.

[8] Egrilmez S, Ates H, Nalcaci S, et al. Surgically induced corneal refractive change following glaucoma surgery: Nonpenetrating trabecular surgeries versus trabeculectomy. J Cataract Refract Surg 2004; 30: 1232-9.

[9] Bland JM, Altman DG. Statistical methods for assesing agreement between two methods of clinical measurement. Lancet 1986; 1: 307-10.

[10] Okamoto F, Okamoto C, Sakata N, et al. Changes in corneal topography after 25 -gauge transconjunctival sutureless vitrectomy versus after 20-gauge standard vitrectomy. Ophthalmology 2007; 114(12): 2138-41.

[11] Yanyali A, Celik E, Horozoglu F, et al. Corneal topographic changes after transconjunctival (25-gauge) sutureless vitrectomy. Am J Ophthalmol 2005; 140(5): 939-41.

[12] Kim YK, Hyon JY, Woo SJ, et al. Surgically induced astigmatism after 23-gauge transconjunctival sutureless vitrectomy. Eye (Lond) 2010; 24(5): 799-804.

[13] Sinha R, Sharma N, Verma L, et al. Corneal topographic changes following retinal surgery. BMC Ophthalmol 2004; 4(1): 10.

[14] Shibata T, Watanabe A, Takashina H, et al. Effect on corneal shape of suturing the scleral wound during 23 -gauge vitreous surgery. Jpn J Ophthalmol 2012; 56(5): 441-4.

\section{(C) Kocatürk et al.; Licensee Bentham Open.}

This is an open access article licensed under the terms of the Creative Commons Attribution Non-Commercial License (http://creativecommons.org/licenses/by-nc/3.0/) which permits unrestricted, non-commercial use, distribution and reproduction in any medium, provided the work is properly cited. 